Atmos. Chem. Phys., 13, 7895-7901, 2013

www.atmos-chem-phys.net/13/7895/2013/

doi:10.5194/acp-13-7895-2013

(C) Author(s) 2013. CC Attribution 3.0 License.

\title{
Influence of observed diurnal cycles of aerosol optical depth on aerosol direct radiative effect
}

\author{
A. Arola ${ }^{1}$, T. F. Eck ${ }^{2,3}$, J. Huttunen ${ }^{1}$, K. E. J. Lehtinen ${ }^{1}$, A. V. Lindfors ${ }^{1}$, G. Myhre ${ }^{4}$, A. Smirnov ${ }^{5,3}$, S. N. Tripathi ${ }^{6}$, \\ and $\mathrm{H} . \mathrm{Yu}^{7,3}$ \\ ${ }^{1}$ Finnish Meteorological Institute, P.O. Box 1627, 70211 Kuopio, Finland \\ ${ }^{2}$ Universities Space Research Association, Columbia, MD, USA \\ ${ }^{3}$ NASA Goddard Space Flight Center, Greenbelt, MD, USA \\ ${ }^{4}$ Center for International Climate and Environmental Research - Oslo (CICERO), Oslo, Norway \\ ${ }^{5}$ Sigma Space Corporation, Lanham, MD, USA \\ ${ }^{6}$ Department of Civil Engineering, Indian Institute of Technology, Kanpur 208016, India \\ ${ }^{7}$ Earth System Science Interdisciplinary Center, University of Maryland, College Park, MD, USA
}

Correspondence to: A. Arola (antti.arola@fmi.fi)

Received: 22 February 2013 - Published in Atmos. Chem. Phys. Discuss.: 19 April 2013

Revised: 28 June 2013 - Accepted: 6 July 2013 - Published: 15 August 2013

\begin{abstract}
The diurnal variability of aerosol optical depth (AOD) can be significant, depending on location and dominant aerosol type. However, these diurnal cycles have rarely been taken into account in measurement-based estimates of aerosol direct radiative forcing (ADRF) or aerosol direct radiative effect (ADRE). The objective of our study was to estimate the influence of diurnal aerosol variability at the top of the atmosphere ADRE estimates. By including all the possible AERONET sites, we wanted to assess the influence on global ADRE estimates. While focusing also in more detail on some selected sites of strongest impact, our goal was to also see the possible impact regionally. We calculated ADRE with different assumptions about the daily AOD variability: taking the observed daily AOD cycle into account and assuming diurnally constant AOD. Moreover, we estimated the corresponding differences in ADREs, if the single AOD value for the daily mean was taken from the the Moderate Resolution Imaging Spectroradiometer (MODIS) Terra or Aqua overpass times, instead of accounting for the true observed daily variability. The mean impact of diurnal AOD variability on $24 \mathrm{~h}$ ADRE estimates, averaged over all AERONET sites, was rather small and it was relatively small even for the cases when AOD was chosen to correspond to the Terra or Aqua overpass time. This was true on average over all AERONET sites, while clearly there can be much stronger impact in individual sites. Examples of some selected sites demonstrated
\end{abstract}

that the strongest observed AOD variability (the strongest morning afternoon contrast) does not typically result in a significant impact on $24 \mathrm{~h}$ ADRE. In those cases, the morning and afternoon AOD patterns are opposite and thus the impact on $24 \mathrm{~h}$ ADRE, when integrated over all solar zenith angles, is reduced. The most significant effect on daily ADRE was induced by AOD cycles with either maximum or minimum AOD close to local noon. In these cases, the impact on $24 \mathrm{~h}$ ADRE was typically around $0.1-0.2 \mathrm{~W} \mathrm{~m}^{-2}$ (both positive and negative) in absolute values, $5-10 \%$ in relative ones.

\section{Introduction}

Aerosols affect the earth's climate directly by scattering and absorbing radiation (direct aerosol effect) and by affecting cloud properties (indirect aerosol effect). Currently, aerosol forcing is the largest uncertainty in assessing the anthropogenic climate change. In IPCC (2007), the scientific understanding of direct and indirect aerosol climate forcing has been designated as "medium-low" and "low", respectively. Therefore, regardless of the recent progress, also the estimate of direct forcing still contains significant uncertainties (Kahn, 2012). Indeed, the study by Loeb and Su (2010) suggested that the quantitative uncertainties reported by the 
IPCC (2007), which were based on the model diversity rather than on aggregated error, are clearly underestimated.

The diurnal variability in aerosol optical depth (AOD) can be significant, depending on location and dominant aerosol type (e.g., Smirnov et al., 2002; Eck et al., 2003; Zhang et al., 2012). These diurnal cycles have rarely been taken into account in measurement-based estimates of aerosol direct radiative forcing (ADRF) or aerosol direct radiative effect (ADRE), the former taking into account the anthropogenic aerosols and the latter both anthropogenic and natural aerosols. However, Christopher et al. (2006) reported that the diurnal variation of dust aerosols could be important for dust radiative forcing calculations. The objective of this study is to provide an estimate of the impact of diurnal AOD variability on the estimates of ADRE at the top of the atmosphere (TOA). This is the first time that the importance of diurnal AOD cycle on ADRE calculations is assessed using data from large number of Aerosol Robotic Network (AERONET) sites. We included all the sites from AERONET (Holben et al., 1998), thus covering a wide range of conditions. We calculated the mean diurnal AOD cycle on a seasonal basis, for each site with enough data, and the related impact of this cycle on TOA ADRE using radiative transfer modeling.

\section{Data and methods}

\subsection{AERONET data}

AERONET is a globally distributed network of automatic sun and sky scanning radiometers that measure at several wavelengths, typically centered at $0.34,0.38,0.44,0.50$, $0.675,0.87,0.94$, and $1.02 \mu \mathrm{m}$. Each band has a full width of approximately $0.010 \mu \mathrm{m}$ at half maximum (FWHM), except for the UV channels that have a FWHM bandpass of $0.002 \mu \mathrm{m}$. These spectral bands are utilized in the direct sun measurements, while four of them are used for the sky radiance: $0.44,0.67,0.87$, and $1.02 \mu \mathrm{m}$. Spectral aerosol optical depth (AOD) is obtained from direct sun measurements, and inversion products of other aerosol optical properties, such as single scattering albedo (SSA), refractive indices and the column-integrated aerosol size distributions above the measurement site are provided at the sky radiance wavelengths (Holben et al., 1998).

In our study, in order to form the diurnal patterns of AOD, we used level 2.0 direct sun data (quality assured; Smirnov et al., 2000) of AOD at $500 \mathrm{~nm}$, which has accuracy of 0.01 at optical air mass (m) of 1 (Eck et al., 1999) and higher accuracy at larger air mass, proportional to $1 \mathrm{~m}^{-1}$. Measurements of AOD are made from air mass of 05:00 in the morning to air mass of 17:00 in the evening. The other wavelengths for radiative transfer calculations were then estimated using the average Ångström exponent based on 380-500 nm (from AERONET direct sun product). The other optical properties
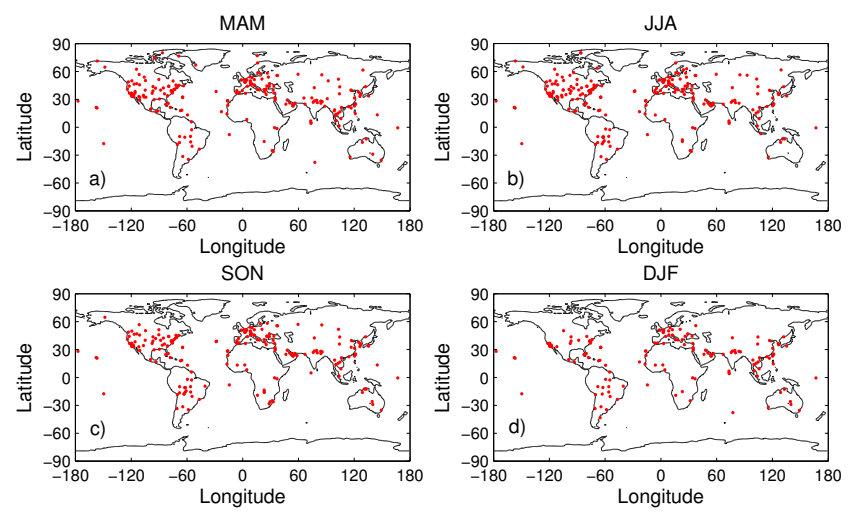

Fig. 1. Included AERONET sites in each season: (a) MAM, (b) JJA, (c) SON, and (d) DJF.

(SSA and asymmetry parameter at four wavelengths) from the inversion products (Dubovik et al., 2002) were used in radiative transfer calculations, as explained in more detail in the following section.

All individual observations of AOD at $500 \mathrm{~nm}$ for a specific day were taken, and the departures from the daily mean AOD were calculated, requiring that there is at least one AOD observation both before and after the local solar noon. Eventually, these hourly departures were averaged for each hour of local solar time, to form the average daily cycle of departures for each site; an example is given by Fig. 2, which is discussed in more detail in the Results section. All the days were included and analyzed on a seasonal basis: March-May (MAM), June-August (JJA), September-November (SON), and December-February (DJF). We required at least 30 days of AOD data within a multi-year season to form the diurnal AOD pattern. The number of included sites is $224,253,208$, and 144 for MAM, JJA, SON, and DJF, respectively. The selected sites in each season are shown in the Fig. 1.

\subsection{Calculation of the radiative effect}

The radiative transfer simulations were performed with the libRadtran package (Mayer and Kylling, 2005). Radiative transfer models of libRadtran have been thoroughly validated and checked against both measurements and other models, for instance recently in Randles et al. (2013). We used twostream solver and so-called correlated $k$ approach with bands from $240.1185 \mathrm{~nm}$ to $3991.003 \mathrm{~nm}$. For the vertical profile, we assumed aerosol extinction decreasing exponentially with height. The AERONET measurements were used as input to these calculations to estimate the diurnally averaged clearsky TOA ADRE for all AERONET sites that had enough data to form the diurnal AOD pattern as described in the previous section. We performed the calculations with a one-hour time step over a $24 \mathrm{~h}$ diurnal cycle with solar insolation of the 15 th day of the middle month of the season to provide the seasonal 

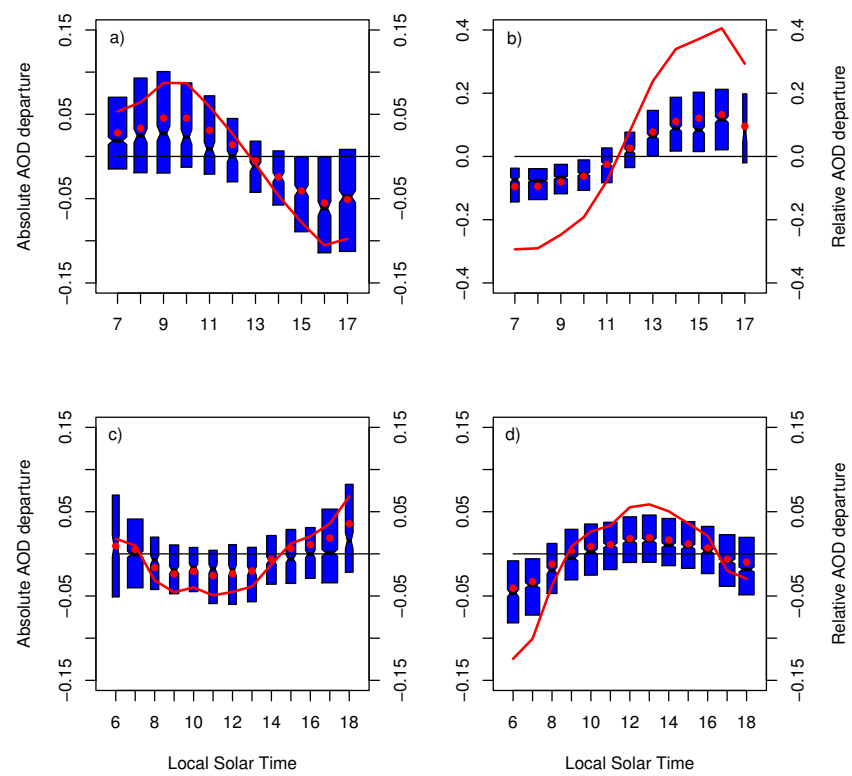

Fig. 2. AOD departures from the daily mean. Box plots give the medians (with 5th/95th percentiles) of absolute AOD departure, and the red solid points provide the mean, in addition. The red line is the relative departure in right axis; the absolute departure in each hour divided by the overall mean AOD of each season and site. The following sites and seasons are shown: (a) Silpakorn University, Thailand MAM; (b) Mexico City, Mexico, DJF; (c) Hamim, United Arab Emirates, JJA; and (d) Blida, Algeria, JJA.

averages. The TOA ADRE calculations were performed with different assumptions about the daily AOD variability:

1. diurnally varying AOD according to observations;

2. no diurnal $\mathrm{AOD}$ variation, $\mathrm{AOD}=$ daily averaged $\mathrm{AOD}$;

3. no diurnal $\mathrm{AOD}$ variation, $\mathrm{AOD}=$ observed $\mathrm{AOD}$ at the MODIS Terra/Aqua overpass time.

Since AODs from the Moderate Resolution Imaging Spectroradiometer (MODIS) data are widely used in ADRF and ADRE calculations, we also wanted to estimate the impact on ADRE, if the single AOD value for the daily mean is taken from the Terra or Aqua overpass times, instead of accounting for the true observed daily variability.

In the following, we will mainly concentrate on the difference between two ADRE estimates; with different assumptions about the diurnal evolution of aerosol optical depth. Therefore, arguably the absolute value of the ADRE in our calculations is less important than the magnitude of the difference between the two ADRE estimates, affected by the diurnal AOD variability only. Regardless of this, we attempted to form the input data for each site to be as site-representative and realistic as possible. Therefore, for instance, we applied the same solar zenith angle dependent MODIS-based surface albedo (black-sky albedo) for each site as that used in the AERONET retrievals (at four wavelengths of the inversion product) as briefly described in Eck et al. (2008). Therefore, in our RT calculations, also the surface albedo exhibited diurnal variability. The surface albedo was linearly interpolated between the inversion data wavelengths. The surface albedo value at $440 \mathrm{~nm}$ was extrapolated to the shorter wavelengths as well, while the wavelengths larger than $1020 \mathrm{~nm}$ were linearly extrapolated so that the surface albedo at $5 \mu \mathrm{m}$ is decreased to 0.01 .

Seasonally averaged single scattering albedo (SSA) and asymmetry parameter were taken at four wavelengths as well from the inversion product and were interpolated and extrapolated to cover the full range of the solar spectrum. We used level 1.5 inversion product, in order to obtain site-specific SSA and asymmetry parameter values also for those sites where the prevailing conditions of AOD at $440 \mathrm{~nm}$ are below 0.4 (which is the AOD limit for the level 2.0 product). However, when we selected the data from the level 1.5 inversion product, we applied all the other level 2.0 AERONET criteria except for the AOD threshold. There are two other justifications for our choice to use level 1.5 product. First, we are interested in ADRE, which decreases as AOD decreases. Thus, although the uncertainty of SSA increases with decreasing AOD, its impact on our calculations decreases as well. Second, and more importantly, our specific interest is in the difference between two ADRE simulations, when the only difference is the diurnal pattern of aerosol optical depth. Therefore, the importance of SSA is further reduced. Nevertheless, we wanted to form as realistic and site-specific input parameters as possible for our ADRE calculations. In addition to aerosol optical properties, also the columnar water vapor measurements (as seasonal averages) from AERONET were used in the calculations.

\section{Results}

Figure 2 shows an example of observed diurnal AOD patterns from four sites. The data are represented as box plots (with 5 and 95 percentiles), in order to give not only the median, but also an impression about the variability of departures in each hour. Moreover, the boxes are drawn with widths proportional to the square roots of the number of observations in each hour. In addition to the medians, which are given by the box plots, the mean departures in each hour are indicated by the solid red points. The red line gives the mean relative departure, showing the absolute departure in each hour divided by the overall mean AOD at $500 \mathrm{~nm}$ in that particular season. This particular choice of sites is based on the inspection of all the results, to select two representative examples of sites with significant AOD variability (Silpakorn University, Mexico City) and less significant diurnal AOD pattern (Hamim, Blida), but the latter having a stronger impact on TOA ADRE (Hamim, Blida), as explained in further detail below. 

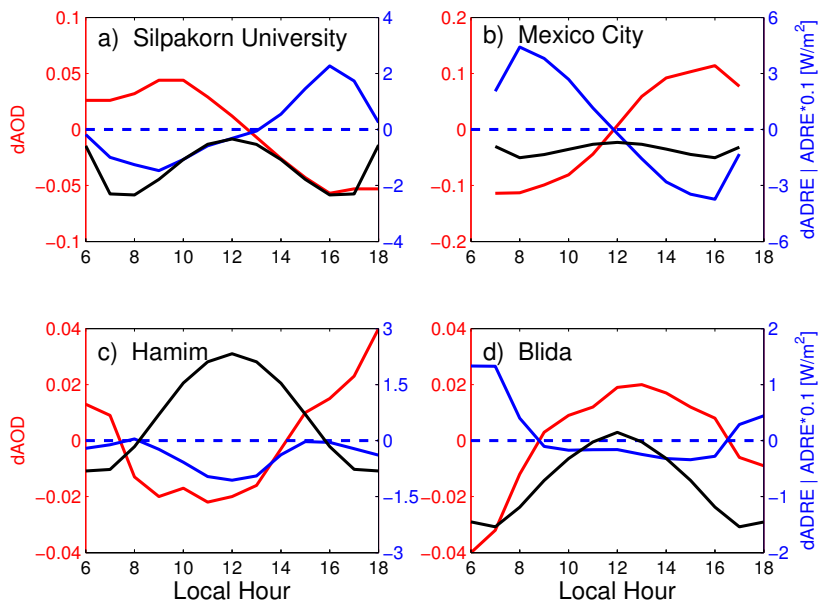

Fig. 3. Hourly AOD departures from the daily mean in red (dAOD, left side $y$ axis) and the instantaneous difference between two ADRE runs (assuming the observed daily AOD variability and with mean daily AOD) in blue (dADRE, right side $y$ axis). Black line shows ADRE with true diurnal AOD cycle (right side $y$ axis); ADRE is multiplied by 0.1 to match the common $y$ axis with dADRE better. Same sites and seasons (and in the same order) as in the Fig. 2.

There can be several different potential reasons for sitespecific diurnal AOD variability, and those have been discussed in more detail in previous studies (e.g., Smirnov et al., 2002; Eck et al., 2003; Zhang et al., 2012). For instance, Gautam et al. (2012) reported a similar diurnal cycle for Silpakorn University, which is shown in Fig. 2. They speculated that one reason for the enhanced aerosol loading in the morning in this biomass burning region may be associated with smoke transport through the night.

Figure 3 shows the same sites as in Fig. 2, and in addition to AOD cycle, the time evolution of the instantaneous difference between two ADRE simulations (dADRE) is also shown, in order to illustrate the impact of diurnal AOD variability on diurnally averaged ADRE estimates. Moreover, ADRE with true diurnal AOD cycle is included (black line), to make it easier to interpret the dADRE pattern, particularly when ADRE can change from cooling to warming. ADRE is multiplied by 0.1 to make it better match the common $y$ scale. Two upper panels show sites with a significant diurnal variability, which however does not translate into equally significant impact on $24 \mathrm{~h}$ ADRE. This is the case, for instance, in Mexico City, which has the strongest morning to afternoon contrast in the measured AOD out of all AERONET sites (note its different $y$ axis scale). However, when temporally integrated over the day, the impact in the morning is compensated in the afternoon, which can be seen in Fig. 3b: although there is a positive ADRE difference before local solar noon, which is about $4.5 \mathrm{~W} \mathrm{~m}^{-2}$ at the maximum at 08:00 local solar time, there is a very similar pattern of opposite
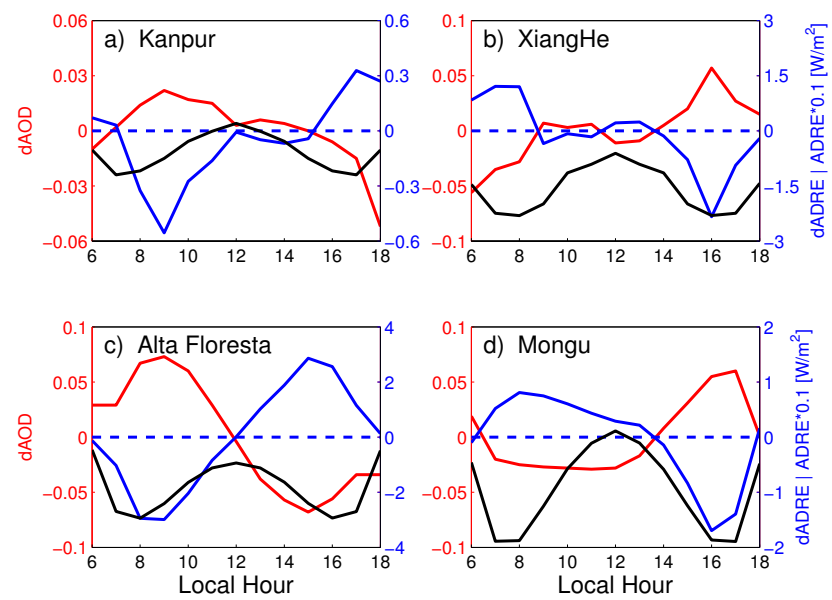

Fig. 4. As in Fig. 3, but for the following sites and seasons: (a) Kanpur, India, MAM; (b) Xianghe, China, MAM; (c) Alta Floresta, Brazil, SON; and (d) Mongu, Zambia, SON. Black line shows ADRE with true diurnal AOD cycle (right side $y$ axis); ADRE is multiplied by 0.1 in all other sites, but by 0.01 in Kanpur.

sign in the afternoon. Therefore, the integrated difference in $24 \mathrm{~h}$ ADRE is eventually only $0.041 \mathrm{~W} \mathrm{~m}^{-2}$.

The bottom panels of Fig. 3, on the other hand, illustrate two sites with clearly less significant daily AOD cycle, yet resulting in more significant impact on the estimate of diurnally averaged ADRE. The main reason for this enhanced impact on dADRE in Hamim $\left(-0.213 \mathrm{~W} \mathrm{~m}^{-2}\right)$, for instance, is that the hours of positive dAOD correspond mostly to those solar zenith angles when ADRE is negative (cooling effect), while during the negative dAOD hours (around noon) ADRE is positive. Therefore, the instantaneous dADRE during almost all the hours is negative (it is only slightly positive at 08:00 local hour), and thus there is no similar compensation to that of the sites shown in the upper panels. In Blida, there is somewhat similar impact, however with the opposite AOD cycle; the largest instantaneous dADRE is formed in the morning hours, when ADRE is clearly negative, which then is not much compensated around noon (when dAOD is positive), since ADRE is clearly reduced and becomes even slightly positive at local noon.

Figure 4 shows four additional AERONET sites that all have long data records, which have been also widely analyzed before. Therefore, we consider it interesting to show here also their diurnal AOD patterns and the impact of these patterns on the calculation of aerosol direct radiative effect. The upper panel plots show two sites, affected heavily by urban pollution (Kanpur in India and Xianghe in China) and additionally by desert dust primarily in MAM (Eck et al., 2010), while the lower panel plots show two sites affected seasonally by strong biomass burning. Note that ADRE (black line) is multiplied by 0.01 in Kanpur and by 0.1 in other sites. Although all these sites are influenced by strong seasonally varying aerosol emissions, it is evident 

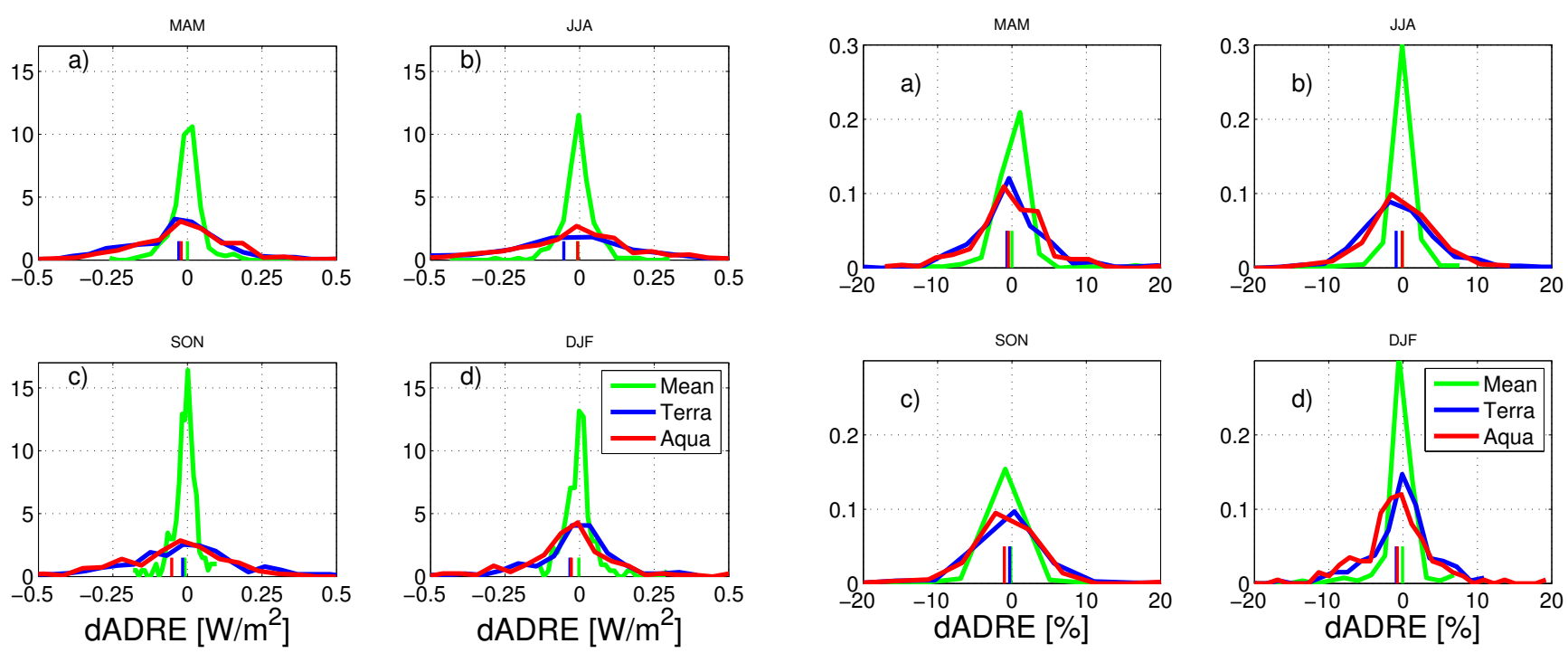

Fig. 5. Histograms of all AERONET sites on a seasonal basis: (a) MAM, (b) JJA, (c) SON, and (d) DJF. Green line is ADRE difference between two AOD assumptions: with observed diurnal variability and assuming daily mean AOD. In the blue line case, AOD is taken from the observed diurnal cycle at Terra overpass time and in the red line case at Aqua overpass time. The histograms are scaled so that the area below each curve equals unity.

(also by the data of other seasons, not shown here) that the diurnal AOD variability does not draw a significant influence on daily averaged direct aerosol effect; it is only slightly negative for all shown cases: $-0.026 \mathrm{~W} \mathrm{~m}^{-2},-0.053 \mathrm{~W} \mathrm{~m}^{-2}$, $-0.014 \mathrm{~W} \mathrm{~m}^{-2}$, and $-0.016 \mathrm{~W} \mathrm{~m}^{-2}$, for Kanpur, Xianghe, Alta Floresta, and Mongu, respectively.

Table 1 provides the ADRE differences in these eight sites for all seasons. In addition, it provides the TOA ADRE values (assuming diurnally varying AOD), to allow an impression about the relative impact of diurnal AOD variability on daily averaged TOA ADRE, which is given also in percentage in the last column. Relatively, the AOD daily variability does not result in very large impact on TOA ADRE. For example, in Hamim (JJA) ADRE is slightly positive (due to the combined effect of high surface albedo and relatively low SSA), which is overestimated by $0.213 \mathrm{~W} \mathrm{~m}^{-2}$ (7.3\%), if constant diurnally averaged AOD is used. Generally, however, the relative impact is lower. And the overall influence, when including a large number of sites, is relatively small. This is evident also from Table 1, which includes additionally the overall statistics of all sites in each season.

The diurnal AOD cycle cannot be captured by using data from polar-orbiting satellites. Therefore, those absolute and relative ADRE differences are also given in the Table 1, when the single AOD value (to represent the daily mean) is taken from MODIS Terra (around 10:30 local solar time) or Aqua (around 13:30 local solar time) overpass times. Now there are clearly cases of much larger influence in daily averaged

Fig. 6. As in Fig. 5, but for relative dADRE difference (dADRE divided by ADRE assuming true diurnal AOD variability).

dADRE. For instance, in Mexico City and DJF season, which exhibited close to zero impact $\left(0.041 \mathrm{~W} \mathrm{~m}^{-2}\right)$ due to the diurnal AOD variability compared to a daily mean, the difference between ADRE with daily AOD variability and AOD taken at satellite overpass time is $-0.83 \mathrm{~W} \mathrm{~m}^{-2}$ and $0.98 \mathrm{~W} \mathrm{~m}^{-2}$ for Terra and Aqua, respectively.

Figure 5 summarizes the difference in daily averaged ADRE, using different assumptions about diurnal AOD variability, including all AERONET sites of each season that had enough data to form the diurnal AOD cycle. Small vertical lines in each color indicate the mean of the distribution. It can be seen that the mean difference in ADRE, due to the diurnal AOD cycle, over all the available AERONET sites is very close to zero. However, there are sites with an impact of around $0.1 \mathrm{~W} \mathrm{~m}^{-2}$ (both positive and negative), and examples of those are given in Figs. 1-4.

Red and blue curves of Fig. 5 illustrate the impact on the $24 \mathrm{~h}$ ADRE, if AOD is taken either at MODIS Terra (around 10:30 local solar time) or Aqua (around 13:30 local solar time) overpass times. For instance in Mexico City and for DJF season, the difference between ADRE with daily AOD variability and AOD taken at satellite overpass time is quite significant. However, the overall mean of these cases (average over all sites) is relatively close to zero, indicating that the use of either Terra or Aqua AOD data does not result in significant systematic global bias, which would be caused by an unaccounted diurnal AOD cycle. The comparison of the subplots of Fig. 5, on the other hand, suggests a slight seasonal dependence; in JJA season the use of Aqua (afternoon) overpass data and in SON Terra data (before noon) better captures the prevailing AOD cycles, from the point of view of their impact on diurnally averaged ADRE. Figure 6 shows the relative dADRE results of all the sites. They are es- 
Table 1. Diurnally averaged ADRE by the diurnally varying AOD; absolute and relative difference between two ADRE simulations, dADRE, assuming the observed daily AOD variability and the following three cases: (1) observed mean daily AOD, (2) AOD at the Terra overpass time, and (3) AOD at Aqua overpass time.

\begin{tabular}{|c|c|c|c|c|c|}
\hline Site & Season & $\begin{array}{r}\text { ADRE } \\
\left(\mathrm{W} \mathrm{m}^{-2}\right)\end{array}$ & $\begin{array}{r}\mathrm{dADRE} \\
\text { mean AOD } \\
\left(\mathrm{W} \mathrm{m}^{-2}\right) /(\%)\end{array}$ & $\begin{array}{r}\text { dADRE } \\
\text { AOD at Aqua time } \\
\left(\mathrm{W} \mathrm{m}^{-2}\right) /(\%)\end{array}$ & $\begin{array}{r}\text { dADRE } \\
\text { AOD at Terra time } \\
\left(\mathrm{W} \mathrm{m}^{-2}\right) /(\%)\end{array}$ \\
\hline Alta Floresta & DJF & -2.31 & $-0.004 /-0.2$ & $-0.103 /-4.5$ & $0.145 / 6.3$ \\
\hline Blida & DJF & -3.02 & $0.061 / 2.0$ & $0.233 / 7.7$ & $-0.247 /-8.2$ \\
\hline Hamim & DJF & 0.54 & $-0.041 /-7.5$ & $-0.048 /-8.8$ & $0.027 / 4.9$ \\
\hline Kanpur & DJF & -8.14 & $-0.050 /-0.6$ & $0.136 / 1.7$ & $0.117 / 1.4$ \\
\hline Mexico City & DJF & -4.94 & $0.041 / 0.8$ & $0.984 / 19.9$ & $-0.827 /-16.7$ \\
\hline Mongu & DJF & -3.19 & $0.003 / 0.1$ & $-0.134 /-4.2$ & $-0.118 /-3.7$ \\
\hline Silpakorn Univ & DJF & -8.71 & $-0.024 /-0.3$ & $0.109 / 1.3$ & $-0.014 /-0.2$ \\
\hline Xianghe & DJF & -5.56 & $-0.008 /-0.1$ & $0.046 / 0.8$ & $0.113 / 2.0$ \\
\hline Alta Floresta & MAM & -1.67 & $0.028 / 1.7$ & $0.025 / 1.5$ & $0.075 / 4.5$ \\
\hline Blida & MAM & -2.72 & $0.026 / 1.0$ & $0.277 / 10.2$ & $-0.016 /-0.6$ \\
\hline Hamim & MAM & 2.28 & $-0.097 /-4.3$ & $-0.068 /-3.0$ & $-0.021 /-0.9$ \\
\hline Kanpur & MAM & -6.27 & $-0.026 /-0.4$ & $0.034 / 0.5$ & $0.124 / 2.0$ \\
\hline Mexico City & MAM & -5.28 & $0.057 / 1.1$ & $1.125 / 21.3$ & $-0.302 /-5.7$ \\
\hline Mongu & MAM & -3.86 & $0.008 / 0.2$ & $0.051 / 1.3$ & $-0.026 /-0.7$ \\
\hline Silpakorn Univ & MAM & -7.29 & $0.014 / 0.2$ & $-0.188 /-2.6$ & $0.487 / 6.7$ \\
\hline Xianghe & MAM & -8.67 & $-0.053 /-0.6$ & $-0.103 /-1.2$ & $0.024 / 0.3$ \\
\hline Alta Floresta & JJA & -3.00 & $0.034 / 1.1$ & $0.128 / 4.3$ & $-0.025 /-0.8$ \\
\hline Blida & JJA & -4.53 & $0.093 / 2.1$ & $0.369 / 8.1$ & $0.245 / 5.4$ \\
\hline Hamim & JJA & 2.93 & $-0.213 /-7.3$ & $-0.070 /-2.4$ & $-0.052 /-1.8$ \\
\hline Kanpur & JJA & -7.48 & $-0.001 /-0.0$ & $0.008 / 0.1$ & $0.107 / 1.4$ \\
\hline Mexico City & JJA & -3.81 & $0.093 / 2.4$ & $0.623 / 16.4$ & $0.102 / 2.7$ \\
\hline Mongu & JJA & -3.38 & $0.004 / 0.1$ & $0.000 / 0.0$ & $-0.140 /-4.2$ \\
\hline Xianghe & JJA & -12.99 & $0.012 / 0.1$ & $0.099 / 0.8$ & $0.038 / 0.3$ \\
\hline Alta Floresta & SON & -9.79 & $-0.014 /-0.1$ & $-0.799 /-8.2$ & $0.710 / 7.2$ \\
\hline Blida & SON & -3.71 & $0.008 / 0.2$ & $0.264 / 7.1$ & $-0.119 /-3.2$ \\
\hline Hamim & SON & 1.44 & $-0.081 /-5.6$ & $-0.001 /-0.1$ & $-0.017 /-1.2$ \\
\hline Kanpur & SON & -9.18 & $-0.008 /-0.1$ & $0.149 / 1.6$ & $0.004 / 0.0$ \\
\hline Mexico City & SON & -3.85 & $0.050 / 1.3$ & $0.795 / 20.6$ & $-0.511 /-13.3$ \\
\hline Mongu & SON & -5.11 & $-0.016 /-0.3$ & $-0.063 /-1.2$ & $-0.327 /-6.4$ \\
\hline Silpakorn Univ & SON & -5.06 & $-0.015 /-0.3$ & $-0.061 /-1.2$ & $-0.057 /-1.1$ \\
\hline Xianghe & SON & -8.42 & $-0.016 /-0.2$ & $-0.035 /-0.4$ & $0.311 / 3.7$ \\
\hline Mean of 144 sites & DJF & -3.57 & $-0.003 /-0.07$ & $-0.028 /-0.8$ & $-0.033 /-0.9$ \\
\hline Mean of 224 sites & MAM & -4.30 & $0.0002 / 0.04$ & $-0.021 /-0.5$ & $-0.029 /-0.7$ \\
\hline Mean of 253 sites & JJA & -5.70 & $-0.007 /-0.1$ & $-0.006 /-0.1$ & $-0.053 /-0.9$ \\
\hline Mean of 208 sites & SON & -5.18 & $-0.008 /-0.2$ & $-0.053 /-1.0$ & $-0.016 /-0.3$ \\
\hline
\end{tabular}

sentially within $\pm 10 \%$, the major part being centered within $\pm 5 \%$.

\section{Conclusions}

The influence of diurnal AOD variability on TOA ADRE estimates, exploiting a large number of AERONET sites, has not been estimated before. We formed the diurnal AOD cycles as departures from daily means, similar to Smirnov et al. (2002) and Zhang et al. (2012), for all the AERONET sites with a sufficient amount of data. We required at least 30 days of data to form the daily cycle, and this resulted in the following numbers of sites in our analy- sis: 224, 253, 208, and 144 for MAM, JJA, SON, and DJF, respectively. We then calculated the influence of these observed patterns on diurnally averaged aerosol direct radiative effect at the top of the atmosphere on a seasonal basis. In addition to the impact due to the observed AOD cycle itself, we also estimated similarly the influence, if using the AOD from satellite overpass times of either Terra or Aqua, as is commonly done.

Examples of some selected sites demonstrated that the strongest observed AOD variability (the strongest morning afternoon contrast) does not typically result in significant impact in $24 \mathrm{~h}$ TOA ADRE, compared to the use of daily mean AOD. In most of those cases, the morning and afternoon 
AOD patterns are opposite, and thus the impact on $24 \mathrm{~h}$ ADRE, when integrated over all solar zenith angles, is clearly reduced (as illustrated in Fig. 3). The most significant effect on daily ADRE was induced by AOD cycle, with either maximum or minimum AOD close to local noon.

In individual sites there can be significant biases in ADRE estimates due to the impact of diurnal AOD variability. However, the mean impact of diurnal AOD variability on $24 \mathrm{~h}$ ADRE estimates, averaged over all AERONET sites, is rather small; it is relatively small even for the cases when AOD is taken either from Terra or Aqua overpass time. This latter finding suggests that, even though there can be more substantial influences regionally or in individual sites, overall the diurnal AOD variability is not a very strong factor influencing the diurnally averaged ADRE. Therefore, the use of AOD data from polar-orbiting satellites does not likely result in significant bias in global ADRE estimates, assuming AERONET sites represent well enough the possible diurnal variabilities.

Acknowledgements. We thank the principal investigators and their staff for establishing and maintaining the AERONET sites used in this study. Antti Arola wants to acknowledge the support from the Academy of Finland (through the grant "Researcher training and research abroad", decision No. 136996). S. N. Tripathi acknowledges the financial support from DST Climate Change Programme.

Edited by: E. Gerasopoulos

\section{References}

Christopher, S. A., Wang, J., Ji, Q., and Tsay, S.-C.: Estimation of diurnal shortwave dust aerosol radiative forcing during PRIDE, J. Geophys. Res., 108, 8596, doi:10.1029/2002JD002787, 2003.

Dubovik, O., Holben, B. N., Eck, T. F., Smirnov, A., Kaufman, Y. J., King, M. D., Tanr, D., and Slutsker, I.: Variability of absorption and optical properties of key aerosol types observed in worldwide locations, J. Atmos. Sci., 59, 590-608, 2002.

Eck, T., Holben, B., Reid, J. S., Dubovik, O., Smirnov, A., O'Neill, N. T., Slutsker, I., and Kinne, S.: Wavelength dependence of the optical depth of biomass burning urban and desert dust aerosols, J. Geophys. Res., 104, 31333-31349, doi:10.1029/1999JD900923, 1999.

Eck, T. F., Holben, B. N., Ward, D. E., Mukelabai, M. M., Dubovik, O., Smirnov, A., Schafer, J. S., Hsu, N. C., Piketh, S. J., Queface, A., Le Roux, J., Swap, R. J., and Slutsker, I.: Variability of biomass burning aerosol optical characteristics in southern Africa during the SAFARI 2000 dry season campaign and a comparison of single scattering albedo estimates from radiometric measurements, J. Geophys. Res., 108, 8477, doi:10.1029/2002JD002321, 2003.

Eck, T. F., Holben, B. N., Reid, J. S., Sinyuk, A., Dubovik, O., Smirnov, A., Giles, D., O’Neill, N. T., Tsay, S. C., Ji, Q., Al Mandoos, A., Ramzan, A., Reid, E. A., Schafer, J. S., Sorokine, M., Newcomb, W., and Slutsker, I.: Spatial and temporal variability of column-integrated aerosol optical properties in the southern
Arabian Gulf and United Arab Emirates in summer, J. Geophys. Res., 113, D01204, doi:10.1029/2007JD008944, 2008.

Eck, T. F., Holben, B. N., Siniuk, A., Pinker, R. T., Goloub, P., Chen, H., Chatenet, B., Li, Z., Singh, R. P., Tripathi, S. N., Reid, J. S., Giles, D. M., Dubovik, O., O’Neill, N. T., and Smirnov, A.: Climatological aspects of the optical properties of fine/coarse mode aerosol mixtures, J. Geophys. Res., 115, D19205, doi:10.1029/2010JD014002, 2010.

Gautam, R., Hsu, N. C., Eck, T. F., Holben, B. N., Janjai, S., Jantarach, T., Tsay, S., and Lau, W. K.: Characterization of aerosols over the Indochina peninsula from satellite-surface observations during biomass burning pre-monsoon season, Atmos. Environ.,78, 51-59, doi:10.1016/j.atmosenv.2012.05.038, 2012.

Holben, B. N., Eck, T. F., Slutsker, I., Tanre, D., Buis, J. P., Setzer, A., Vermote, E., Reagan, J. A., Kaufman, Y., Nakajima, T., Lavenu, F., Jankowiak, I., and Smirnov, A.: AERONET - A federated instrument network and data archive for aerosol characterization, Rem. Sens. Environ., 66, 1-16, 1998.

Intergovernmental Panel on Climate Change (IPCC), Climate Change 2007: The Scientific Basis, Contribution of Working Group I to the Fourth Assessment Report of the Intergovernmental Panel on Climate Change, edited by: Solomon, S., Qin, D., Manning, M., Chen, Z., Marquis, M., Averyt, K. B., Tignor, M. and Miller, H. L., Cambridge Univ. Press, New York, 2007.

Kahn, R.: Reducing the Uncertainties in Direct Aerosol Radiative Forcing Surveys in Geophysics, Surv. Geophys., 33, 701-721, doi:10.1007/s10712-011-9153-z, 2012.

Loeb, N. G. and Su, W.: Direct aerosol radiative forcing uncertainty based on a radiative perturbation analysis, J. Climate, 23, 52885293, 2010.

Mayer, B. and Kylling, A.: Technical note: The libRadtran software package for radiative transfer calculations - description and examples of use, Atmos. Chem. Phys., 5, 1855-1877, doi:10.5194/acp-5-1855-2005, 2005.

Randles, C. A., Kinne, S., Myhre, G., Schulz, M., Stier, P., Fischer, J., Doppler, L., Highwood, E., Ryder, C., Harris, B., Huttunen, J., Ma, Y., Pinker, R. T., Mayer, B., Neubauer, D., Hitzenberger, R., Oreopoulos, L., Lee, D., Pitari, G., Di Genova, G., Quaas, J., Rose, F. G., Kato, S., Rumbold, S. T., Vardavas, I., Hatzianastassiou, N., Matsoukas, C., Yu, H., Zhang, F., Zhang, H., and $\mathrm{Lu}$, P.: Intercomparison of shortwave radiative transfer schemes in global aerosol modeling: results from the AeroCom Radiative Transfer Experiment, Atmos. Chem. Phys., 13, 2347-2379, doi:10.5194/acp-13-2347-2013, 2013.

Smirnov, A., Holben, B. N., Eck, T. F., Dubovik, O., and Slutsker, I.: Cloud-Screening and Quality Control Algorithms for the AERONET Database, Remote Sens. Environ., 73, 337-349, doi:10.1016/S0034-4257(00)00109-7, 2000.

Smirnov, A., Holben, B. N., Eck, T. F., Slutsker, I., Chatenet, B., and Pinker, R. T.: Diurnal variability of aerosol optical depth observed at AERONET (Aerosol Robotic Network) sites, Geophys. Res. Lett., 29, 2115, doi:10.1029/2002GL016305, 2002.

Zhang, Y., Yu, H., Eck, T. F., Smirnov, A., Chin, M., Remer, L. A., Bian, H., Tan, Q., Levy, R., Holben, B. N., and Piazolla, S.: Aerosol daytime variations over North and South America derived from multiyear AERONET measurements, J. Geophys. Res., 117, D05211, doi:10.1029/2011JD017242, 2012. 